Bladder augmentation revision without additional bowel harvest

\title{
Opportunities for augmentation cystoplasty revision without additional bowel harvest: “Hourglass” deformity or non-detubularized augment
}

Joseph J. Pariser; Sean P. Elliott

University of Minnesota, Minneapolis, MN, United States

Cite as: Can Urol Assoc J 2018 October 15; Epub ahead of print. http://dx.doi.org/10.5489/cuaj.5548

Published online October 15, 2018

$* * *$

\section{Abstract}

Introduction: We describe our experience performing bladder augmentation revision without additional bowel harvest for certain suboptimal cystoplasty configurations.

Methods: We identified patients with prior bladder augmentation who underwent augmentation revision without additional bowel harvest at our institution. These patients were identified to have either "hourglass" deformity or non-detubularized augment previously. Revision was performed using an open technique by detaching the prior augment and performing detubularization and/or completion cystotomy as needed. Baseline characteristics, perioperative courses, and followup information were reviewed. Pre- and postoperative cystography and urodynamics were assessed.

Results: Seven patients underwent bladder augmentation revision without the use of additional bowel. Three patients were found to have a non-detubularized augment, while the other four had a narrow connection from the native bladder to augment. Cystography demonstrated correction of "hourglass" deformity for the four patients, and urodynamics revealed resolution of phasic contractions after detubularization. Six of seven patients reported significant improvements in symptoms, such as frequency, urgency, and incontinence. One patient ultimately required Indiana pouch urinary diversion. All patients are performing intermittent catheterization at last followup.

Conclusions: Patients with a prior bladder augmentation with inadequate urine storage should have testing to identify the possibility of a non-detubularized augment or "hourglass" deformity. These patients can be safely offered a revision without the need for additional bowel harvest. 


\section{Introduction}

Augmentation cystoplasty is effective in reducing bladder storage pressures and increasing bladder storage volume. This is achieved through (1) a full-length cystotomy that disrupts the bladder's ability to create an effective detrusor contraction, and (2) the addition of detubularized bowel of sufficient size to create a high-volume, low-pressure reservoir.

When a patient has persistent urinary incontinence, recurrent urinary tract infections or hydronephrosis after augmentation cystoplasty, we perform urodynamics (UDS) and cystoscopy to evaluate for bladder stone, foreign body, inadequate mucous evacuation or other irritants. In the setting of elevated pressures on urodynamics without bladder irritants on cystoscopy, the technique of the cystoplasty should be evaluated. Technical aspects of augmentation cystoplasty that can lead to persistently elevated pressures include: (1) incomplete cystotomy, (2) nondetubularized bowel used in the augmentation, (3) sigmoid colon used in the augmentation, or (4) insufficient amount of bowel used for the augmentation or atrophy of the segment that was used.

Management of persistently elevated pressures should start with medical therapy: oral antimuscarinics followed by intra-detrusor injection of onabotulinum toxin; this will control symptoms in many patients. Occasionally, we encounter patients with elevated pressures who have symptoms refractory to these interventions; in these people we consider revision of the augmentation cystoplasty. In some augment revisions, the use of an additional bowel segment is required to achieve adequate storage volume. However, in this manuscript we describe our experience with those in whom the cause of the persistently elevated pressures appeared to be either inadequate cystotomy or failure to detubularize the bowel. These are unique patients because we are able to achieve good results with an augmentation cystoplasty revision that does not involve the addition of more bowel.

\section{Methods}

After institutional review board approval, our neurogenic bladder database was queried for adult patients (age 18 or older) who underwent augmentation cystoplasty or revision between 20062018. For this type of retrospective study, formal consent was not required. Individual chart review was also performed to include only those revision procedures in which no additional bowel harvest was performed during revision.

Preoperatively, video UDS were performed for patients with prior bladder augmentation who presented with storage-related complaints. Cystoscopy was also performed to confirm suspicion on cystography of inadequate cystotomy leading to "hourglass deformity".

Surgery involved a midline laparotomy through the prior incision. Lysis of adhesions was the norm in all cases. After identification of the anatomic configuration of the augmentation including its pedicle (and sometimes catheterizable channel), the bowel was freed completely from its prior anastomosis to the bladder. In cases of inadequate cystotomy, a completion sagittal cystotomy was then performed to $1 \mathrm{~cm}$ from the bladder neck anteriorly and $1 \mathrm{~cm}$ from the trigonal ridge posteriorly. In cases where it appeared the bowel had not been detubularized 
during the initial augmentation, we then performed complete longitudinal detubularization along the antimesenteric border after circumferential detachment from the native bladder. We deviated from this aggressive approach in one early case in which we only extended the cystotomy anteriorly and only performed a Y-V-plasty of the incompletely detubularized bowel; this led to poor outcomes. Cystoplasty was performed in all cases using 3-0 PDS running suture. A pelvic drain was left in all cases. Continuous catheter drainage was performed for one month postoperatively, then patients resumed intermittent catheterization.

Demographic and perioperative data were compiled. The primary outcome was improvement of symptoms related to inadequate urine storage, such as urgency and incontinence. Additionally, pre- vs. post-operative urodynamic and cystographic studies were compared when available.

\section{Results}

Of the 102 patients in the database who underwent initial augmentation cystoplasty or revision, seven patients were confirmed to have no additional bowel used during a revision. All patients were, coincidentally, female. Median age at revision was 41 years old (range 25-53). Median time from initial augmentation was 17 years (range 1-26), and all original augmentations had been performed at other institutions. Median BMI was $28 \mathrm{~kg} / \mathrm{m}^{2}$ (range 19-44). Indications for initial augmentation cystoplasty included spina bifida in two patients, spinal cord injury in two, multiple sclerosis in one, childhood rhabdomyosarcoma in one and Hinman's Syndrome in one. Information regarding individual patient characteristics, perioperative courses, and follow-up are found in Table 1.

Four patients originally had augmentation performed with detubularized and reconfigured ileum but had an "hourglass deformity" identified on cystoscopy and/or cystogram, indicative on an inadequate cystotomy. A pre- and postoperative cystogram for Patient 1 is demonstrated in Figure 1. Three other patients had augmentation with non-detubularized colon. Cystography images are shown in Figure 2. Five patients had catheterizable channels while two catheterized per urethra. Of the five catheterizable channels, four underwent revision during time of augmentation revision to correct a short tunnel or stomal stenosis. Median operative time was 249 min (range 210-270). A significant lysis of intra-abdominal adhesions was reported in all cases.

Four patients (57\%) developed perioperative complications: three surgical site infections or UTIs and one alcohol withdrawal. One patient who underwent concomitant incisional hernia repair with general surgery developed a recurrence.

At last follow-up, 6/7 patients reported improvement in urinary storage symptoms. Specifically, complaints of frequency, urgency, nocturia, and incontinence were all improved when present preoperatively. Postoperative UDS were performed for patients with nondetubularized augmentation, which revealed complete resolution of phasic contractions seen preoperatively (Figure 3). One patient with Hinman’s Syndrome had progressive symptoms after Y-V-plasty alone. She ultimately opted for cystectomy with Indiana Pouch urinary diversion. All 
patients were performing intermittent catheterization at the time of last follow-up. Median follow-up was 5 months (range 1-70).

\section{Discussion}

Adult patients with storage symptoms after bladder augmentation represent a clinical dilemma. It is not uncommon to require antimuscarinics or intradetrusor onabotulinum toxin ${ }^{1,2}$ after augmentation; however, when symptoms persist, one should consider whether revision of augmentation cystoplasty is indicated.

Bladder augmentation was popularized by Couvelaire in the 1950s for contracted bladders affected by tuberculosis. ${ }^{3}$ Further improvements by Bramble and Mundy in the 1980s included the development of the "clam cystoplasty" to completely bivalve the bladder, which was not performed in a widespread fashion previously. ${ }^{4,5}$ A variety of other alternatives to modern "clam” augmentation cystoplasty using ileum that have generally fallen out of favor include autoaugmentation (detrusor myomectomy) ${ }^{6}$, gastrocystoplasty ${ }^{7}$, and the use of nondetubularized bowel. ${ }^{8}$

During initial bladder augmentation, detubularization of the isolated bowel segment is recommended to decrease peristaltic contractions and increase compliance. ${ }^{9}$ There is also some concern that non-detubularized bowel may increase risk of perforation given uneven pressure distributions compared to a spherical bladder. ${ }^{8}$ Additionally, a wide sagittal or coronal cystotomy should be performed to "clam-shell” the bladder. ${ }^{10}$ This optimizes compliance by preventing a small channel from the native bladder to the intestinal patch, which can cause the augmentation to inappropriately act as a diverticulum. The cystographic appearance resulting from a small channel has been dubbed an "hourglass deformity" given the semblance to old-fashioned timekeepers.

Children with congenital urological issues who undergo bladder augmentation are living longer into adulthood. For example, spina bifida is the most common permanently disabling congenital birth defect in the United States. Historically, life expectancy was dismal with up to $90 \%$ of patients dying in the first few years of life when untreated. ${ }^{11}$ Steady improvements in neurosurgical and urologic care over the last 50-60 years have allowed for over $90 \%$ of individuals to survive into adulthood. ${ }^{12}$ The management of such patients represents one aspect of the growing field of urologic congenitalism. ${ }^{13}$ In our transitional urology clinic, we frequently see adult patients who underwent augmentation cystoplasty and subsequent revisions as children with a variety of acute or chronic urologic complaints.

Unfortunately, operative reports may be unavailable when the original surgery was performed decades earlier in another hospital. Therefore, surgeons must rely on careful interpretation of video UDS and cystoscopy to assess where improvements may be made in the setting of a previous augmentation cystoplasty. In some cases, particularly for augmentations performed in the latter part of the $20^{\text {th }}$ Century, improvements can sometimes be made without harvesting additional bowel. Our patients experienced significant improvement in symptoms by 
extending the prior cystotomy so as to correct an hourglass deformity of the augmentation or in other cases, detubularizing a segment of bowel that had not been detubularized originally.

With heterogenous techniques that have evolved over time, surgical planning for patients with prior augmentation cystoplasty with poor compliance is challenging. It can be difficult to determine whether to consider revision of augmentation or simply offer urinary diversion. Moreover, avoiding the use of additional bowel is appealing to decrease morbidity but risks a poor outcome as the exposed surface area of the augmented segment after revision is theoretically unchanged.

In our series, we identified seven patients who had bladder configurations amenable to augmentation cystoplasty revision without the need for additional bowel harvest. These patients included four with an "hourglass" deformity and three with an augment fashioned as a nondetubularized bowel acting as a "chimney". These configurations are now generally accepted as cautionary tales when discussing modern augmentation cystoplasty techniques. ${ }^{14-16}$

Surgical revisions for augmentation cystoplasty have been reported scarcely in the urologic literature. Vajda et al. reported on five patients who underwent prior augmentation, with more than half as gastrocystoplasty. ${ }^{17}$ However, all of their patients underwent re-augmentation with a new bowel segment. A group from Johns Hopkins recently reported on 17 patients with bladder exstrophy with prior augmentation who underwent re-augmentation. ${ }^{15}$ One patient in their series was noted to have an "hourglass" deformity though it was unclear if additional bowel was used during revision. A previous case report from Alhazmi discussed a single case of revision of a bladder augmentation with an "hourglass" deformity without using additional bowel with a good clinical outcome.

Some limitations of our retrospective study should be mentioned. Notably, our series is small ( $n=7)$ so augmentation revision without additional bowel harvest should be reserved for select anatomical configurations. While our patients ultimately did well, there is no comparison group, which may have shed light on the potential benefits of our approach compared to alternatives. Lastly, some of the patients had short followup, which prevents long-term analysis of our approach.

\section{Conclusion}

Patients with persistent urinary storage symptoms after bladder augmentation should be evaluated for reversible causes such as urinary tract infection, bladder stone or retained mucous. When these have been ruled out and symptoms persist despite medical therapy with antimuscarinics or intradetrusor onabotulinum toxin injection, they should have testing to identify the possibility of a non-detubularized augment or "hourglass" deformity. These patients can be offered a revision without the need for additional bowel harvest. 


\section{References}

1. Apostolidis A, Popat R, Harper M, et al: Successful treatment with botulinum toxin A after failed augmentation ileocystoplasty. Nat. Clin. Pract. Urol. 2007; 4: 280-4.

2. Mishra V, Pakzad M, Hamid R, et al: The outcome of intravesical onabotulinum toxin injections for salvage therapy of refractory detrusor overactivity following augmentation enterocystoplasty. J. Clin. Urol. 2016; 9: 166-9.

3. Couvelaire R: [The "little bladder" of genito-urinary tuberculosis; classification, site and variants of bladder-intestine transplants]. J. Urol. Medicale Chir. 1950; 56: 381-434.

4. Bramble FJ: The treatment of adult enuresis and urge incontinence by enterocystoplasty. Br. J. Urol. 1982; 54: 693-6.

5. Mundy AR and Stephenson TP: "Clam” ileocystoplasty for the treatment of refractory urge incontinence. Br. J. Urol. 1985; 57: 641-6.

6. Cartwright PC and Snow BW: Bladder autoaugmentation: early clinical experience. J. Urol. 1989; 142: 505-8.

7. Mingin GC, Stock JA and Hanna MK: Gastrocystoplasty: long-term complications in 22 patients. J. Urol. 1999; 162: 1122-5.

8. Metcalfe PD, Casale AJ, Kaefer MA, et al: Spontaneous bladder perforations: a report of 500 augmentations in children and analysis of risk. J. Urol. 2006; 175: 1466-70.

9. Goldwasser B, Barrett DM, Webster GD, et al: Cystometric properties of ileum and right colon after bladder augmentation, substitution or replacement. J. Urol. 1987; 138: 1007-8.

10. Stein R, Schröder A and Thüroff JW: Bladder augmentation and urinary diversion in patients with neurogenic bladder: surgical considerations. J. Pediatr. Urol. 2012; 8: 15361.

11. Lorber J: Results of treatment of myelomeningocele. An analysis of 524 unselected cases, with special reference to possible selection for treatment. Dev. Med. Child Neurol. 1971; 13: 279-303.

12. Borgstedt-Bakke JH, Fenger-Grøn M and Rasmussen MM: Correlation of mortality with lesion level in patients with myelomeningocele: a population-based study. J. Neurosurg. Pediatr. 2017; 19: 227-31.

13. Eswara JR, Kielb S, Koyle MA, et al: The Recommendations of the 2015 American Urological Association Working Group on Genitourinary Congenitalism. Urology 2016; 88: $1-7$.

14. González R, Ludwikowski B and Horst M: Determinants of success and failure of seromuscular colocystoplasty lined with urothelium. J. Urol. 2009; 182: 1781-4.

15. Benz KS, Jayman J, Doersch K, et al: Bladder Re-augmentation in Classic Bladder Exstrophy: Risk Factors and Prevention. Urology 2018.

16. Alhazmi HH: Hourglass bladder after ileocystoplasty (case report). Ann. Saudi Med. 2015; 35: 403-5.

17. Vajda P, Buyukunal CSN, Soylet Y, et al: A therapeutic method for failed bladder augmentation in children: re-augmentation. BJU Int. 2006; 97: 816-9. 


\section{Bladder augmentation revision without additional bowel harvest}

\section{Figures and Tables}

Fig. 1. Cystography of patient with prior ileal bladder augmentation with "hourglass" deformity (left: preoperative; right: postoperative).

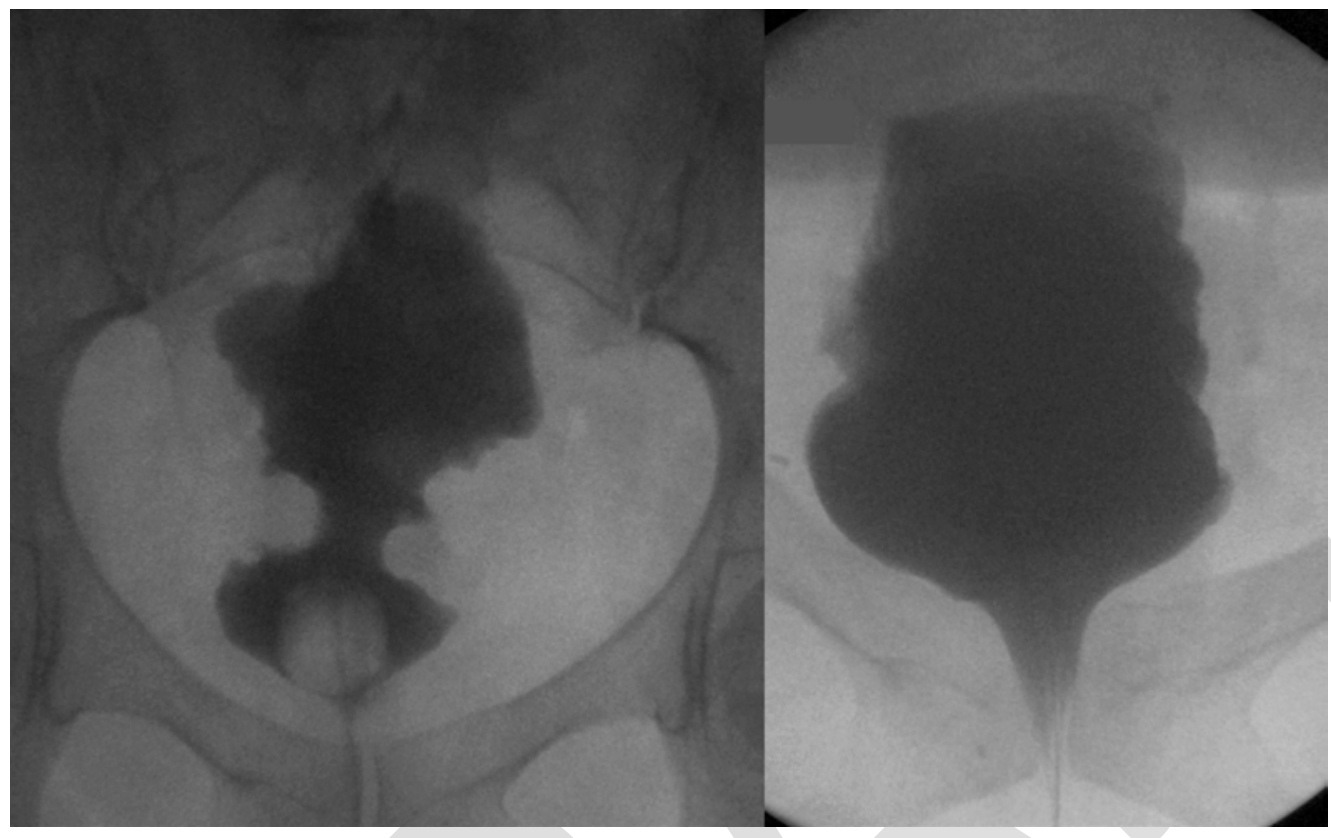

Fig. 2. Cystography of patient with prior bladder augmentation using non-detubularized colon segment (left: preoperative; right: postoperative).

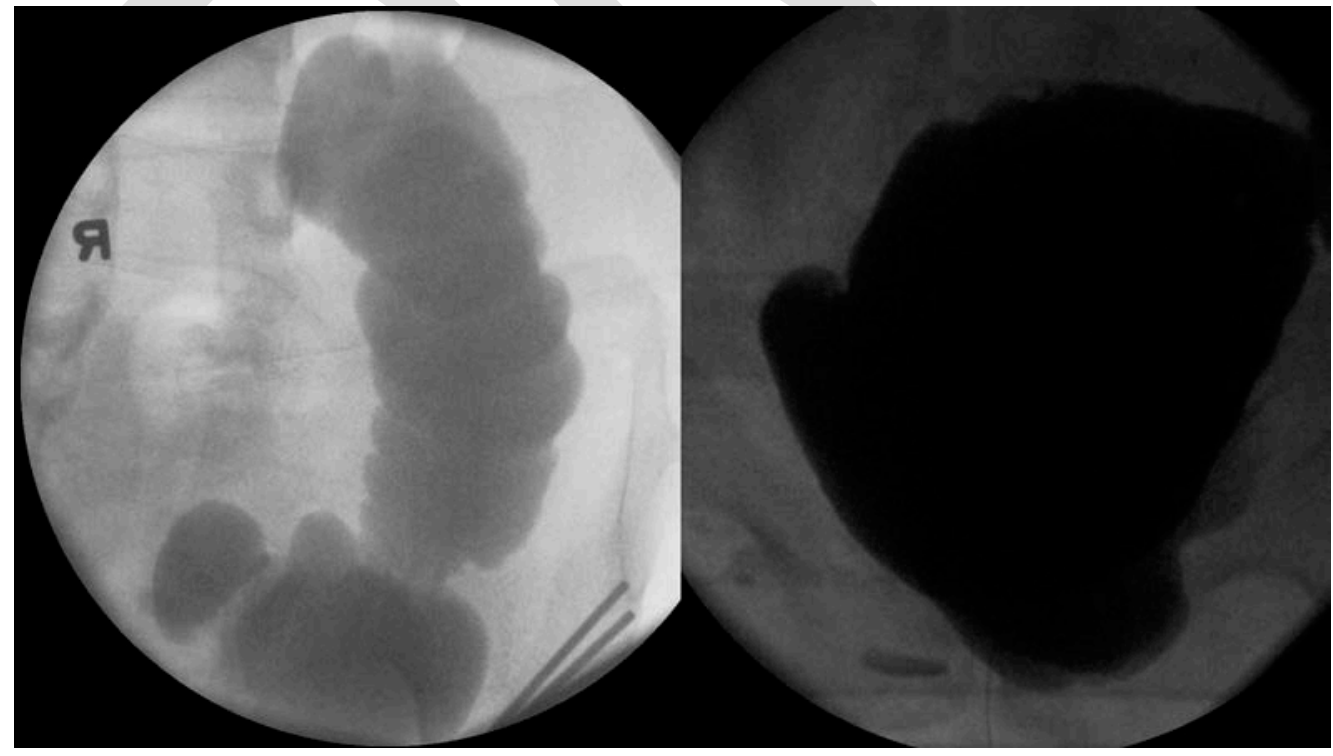


Fig. 3. Urodynamic tracings of patient with prior bladder augmentation using non-detubularized colon segment (left: preoperative; right: postoperative; note phasic contractions in preoperative detrusor pressure).

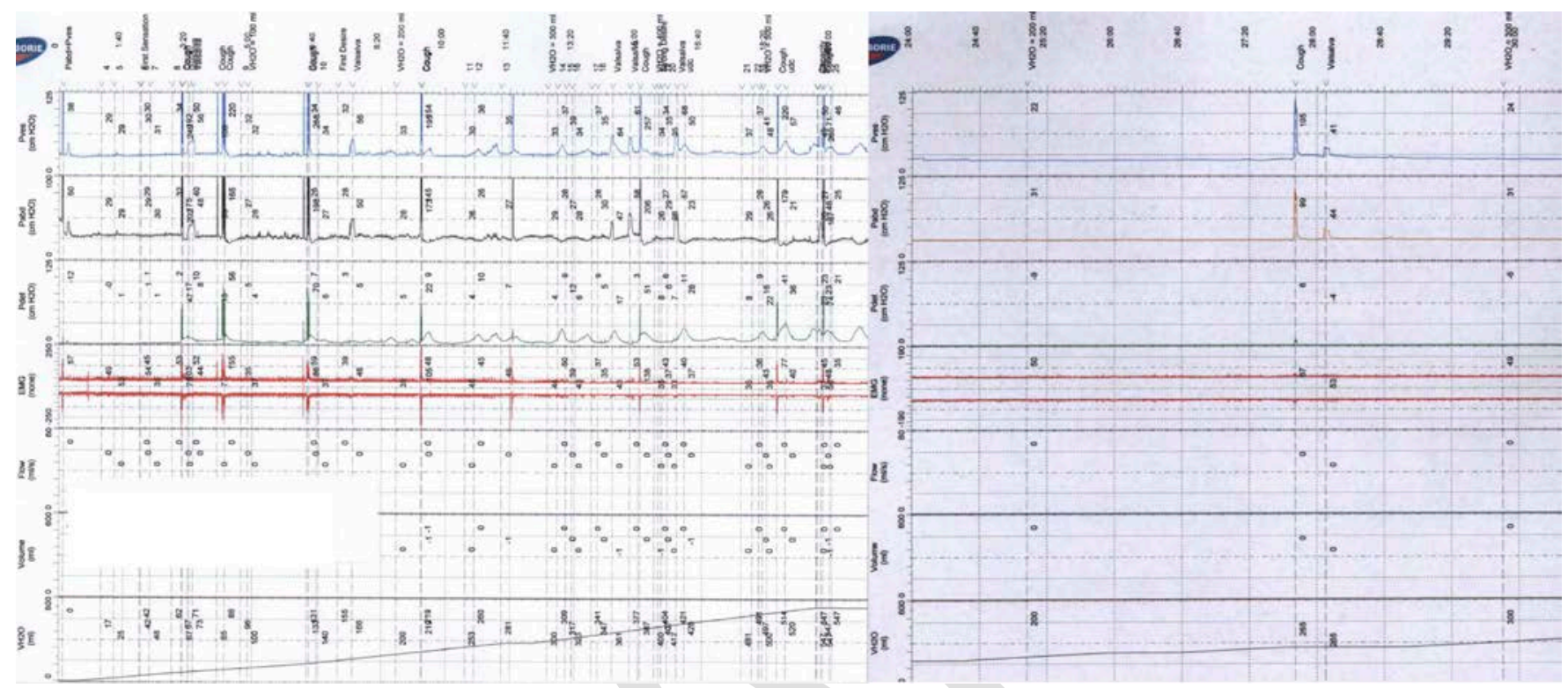


Bladder augmentation revision without additional bowel harvest

\begin{tabular}{|c|c|c|c|c|c|c|c|c|c|c|c|c|}
\hline Pt & $\begin{array}{c}\text { Age at prior } \\
\text { augmentation }\end{array}$ & $\begin{array}{l}\text { Age at } \\
\text { revision }\end{array}$ & Diagnosis & $\begin{array}{c}\text { Augmentation } \\
\text { type }\end{array}$ & $\begin{array}{c}\begin{array}{c}\text { Catheterizable } \\
\text { channel }\end{array} \\
\end{array}$ & $\begin{array}{c}\text { Type of } \\
\text { deformity }\end{array}$ & $\begin{array}{c}\text { Concomitant } \\
\text { procedures }\end{array}$ & $\begin{array}{c}\text { Preoperative } \\
\text { indication }\end{array}$ & $\begin{array}{l}\text { Perioperative } \\
\text { complication } \\
\end{array}$ & $\begin{array}{c}\text { Clavien } \\
\text { grade }\end{array}$ & $\begin{array}{l}\text { Symptoms } \\
\text { at last FU }\end{array}$ & $\begin{array}{c}\text { FU } \\
(\mathrm{mos})\end{array}$ \\
\hline 1 & 15 & 41 & Rhabdomyosarcoma & Ileum & None & Hourglass & None & $\begin{array}{l}\text { Frequency, } \\
\text { urgency, } \\
\text { nocturia }\end{array}$ & $\begin{array}{c}\text { Alcohol } \\
\text { withdrawal } \\
\text { requiring ICU }\end{array}$ & 4 & $\begin{array}{c}\text { No } \\
\text { complaints }\end{array}$ & 5 \\
\hline 2 & 18 & 42 & Spina bifida & Left colon & None & $\begin{array}{c}\text { Non- } \\
\text { detubularized }\end{array}$ & $\begin{array}{l}\text { Mucous } \\
\text { fistula } \\
\text { takedown, } \\
\text { incisional } \\
\text { hernia repair }\end{array}$ & $\begin{array}{c}\text { UI, phasic } \\
\text { contractions on } \\
\text { UDS }\end{array}$ & $\begin{array}{c}\text { Wound } \\
\text { infection, } \\
\text { pelvic } \\
\text { abscess, UTI }\end{array}$ & 3 & $\begin{array}{c}\text { Recurrent } \\
\text { hernia, few } \\
\text { UTIs, } \\
\text { symptoms } \\
\text { improved } \\
\end{array}$ & 41 \\
\hline 3 & 33 & 43 & Multiple sclerosis & Ileum & Ileal Monti & Hourglass & $\begin{array}{c}\text { Monti } \\
\text { channel } \\
\text { tunneling }\end{array}$ & $\begin{array}{l}\text { UI from stoma } \\
\text { and urethra }\end{array}$ & None & 0 & $\begin{array}{c}\text { Symptoms } \\
\text { improved }\end{array}$ & 2 \\
\hline 4 & 36 & 53 & Spinal cord injury & Ileum & Mitrofanoff & Hourglass & $\begin{array}{l}\text { YV-plasty of } \\
\text { Mitrofanoff }\end{array}$ & UI & None & 0 & $\begin{array}{l}\text { Symptoms } \\
\text { improved; } \\
\text { mild } \\
\text { nocturnal } \\
\text { incontinence } \\
\text { at high urine } \\
\text { volumes }\end{array}$ & 6 \\
\hline 5 & 8 & 25 & Spina bifida & Ileum & Mitrofanoff & Hourglass & None & $\begin{array}{c}\text { Worsening } \\
\text { hydronephrosis } \\
\text { and recurrence } \\
\text { pyelonephritis }\end{array}$ & $\begin{array}{l}\text { Wound } \\
\text { infection }\end{array}$ & 2 & $\begin{array}{c}\text { Symptoms } \\
\text { improved }\end{array}$ & 2 \\
\hline 6 & 11 & 31 & Hinman's syndrome & Ileum & Mitrofanoff & $\begin{array}{c}\text { Non- } \\
\text { detubularized }\end{array}$ & $\begin{array}{l}\text { Monti } \\
\text { revision }\end{array}$ & $\begin{array}{c}\text { Urge } \\
\text { incontinence }\end{array}$ & UTI & 2 & $\begin{array}{l}\text { Failed; } \\
\text { underwent } \\
\text { cystectomy, } \\
\text { Indiana } \\
\text { pouch }\end{array}$ & 70 \\
\hline 7 & 35 & 36 & Spinal cord injury & Colon & Tapered Ileum & $\begin{array}{c}\text { Non- } \\
\text { detubularized }\end{array}$ & $\begin{array}{c}\text { Redo bladder } \\
\text { neck closure, } \\
\text { channel } \\
\text { revision }\end{array}$ & UI and SUI & None & 0 & $\begin{array}{c}\text { No } \\
\text { complaints }\end{array}$ & 1 \\
\hline
\end{tabular}




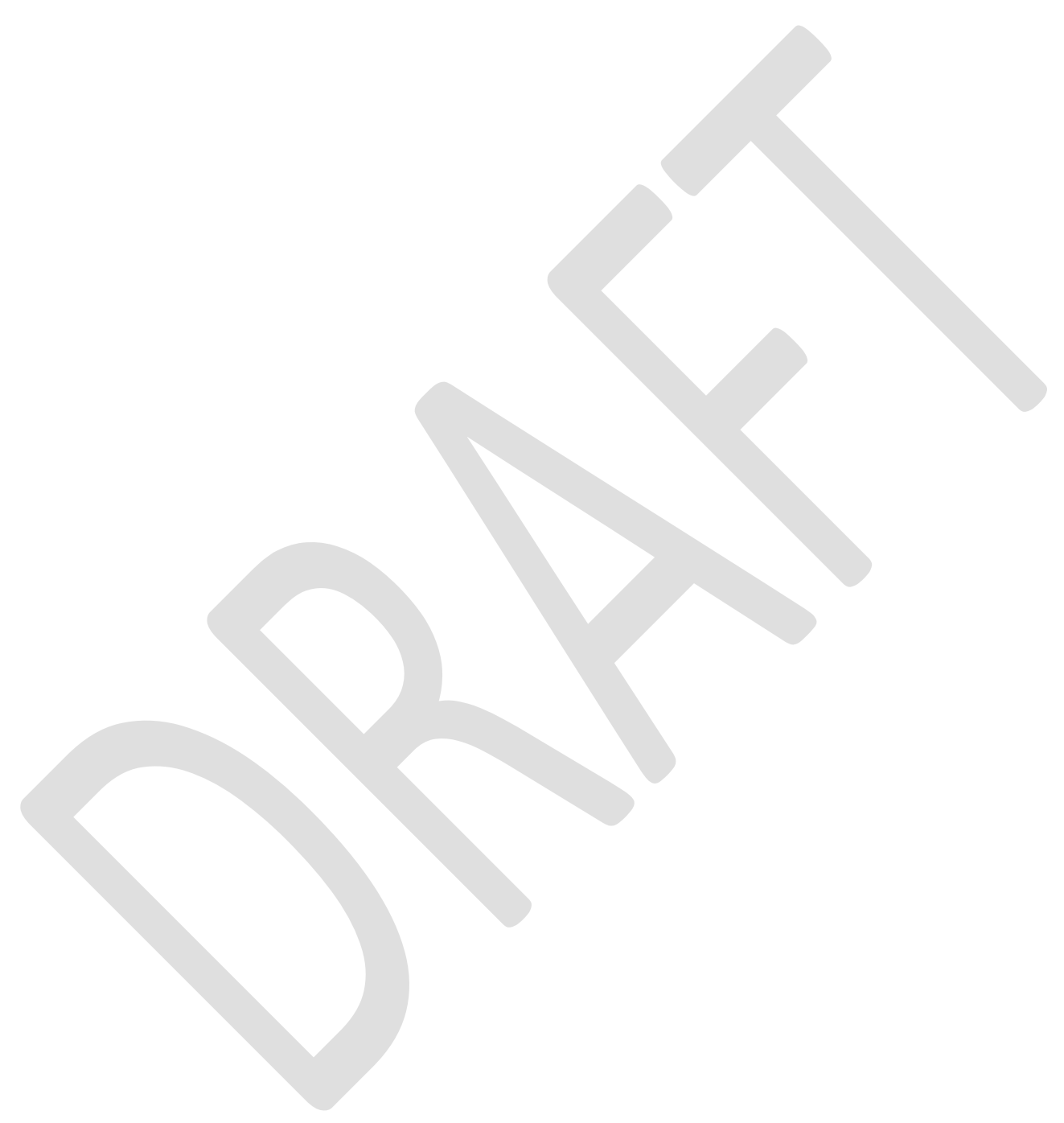

